\title{
Understanding Patient Perspectives on Medication Adherence in Asthma: A Targeted Review of Qualitative Studies
}

This article was published in the following Dove Press journal: Patient Preference and Adherence

\author{
Suvina Amin' \\ Mena Soliman $\mathbb{D}^{2}$ \\ Andrew Mclvor (D) $^{3}$ \\ Andrew Cave $\mathbb{D}^{4}$ \\ Claudia Cabrera ${ }^{5}$ \\ 'US Oncology Medical Affairs, \\ AstraZeneca, Gaithersburg, MD, USA; \\ ${ }^{2}$ BioPharmaceuticals Medical (Europe and \\ Canada), AstraZeneca, Mississauga, ON, \\ Canada; ${ }^{3}$ Department of Medicine, \\ Firestone Institute for Respiratory \\ Health, St. Joseph's Healthcare and \\ McMaster University, Hamilton, ON, \\ Canada; ${ }^{4}$ Department of Family Medicine, \\ University of Alberta, Edmonton, AL, \\ Canada; ${ }^{5}$ BioPharmaceuticals Medical \\ (Evidence), AstraZeneca, Gothenburg, \\ Sweden
}

\begin{abstract}
Adherence to asthma medications is generally poor and undermines clinical outcomes. Poor adherence is characterized by underuse of inhaled corticosteroids (ICS), often accompanied by over-reliance on short-acting $\beta_{2}$-agonists for symptom relief. To identify drivers of poor medication adherence, a targeted literature search was performed in MEDLINE and EMBASE for articles presenting qualitative data evaluating medication adherence in asthma patients ( $\geq 12$ years old), published from January 1, 2012 to February 26, 2018. A thematic analysis of 21 relevant articles revealed several key themes driving poor medication adherence, including asthma-specific drivers and more general drivers common to chronic diseases. Due to the episodic nature of asthma, many patients felt that their daily life was not substantially impacted; consequently, many harbored doubts about the accuracy of their diagnosis or were in denial about the impact of the disease and, in turn, the need for long-term treatment. This was further compounded by poor patient-physician communication, which contributed to suboptimal knowledge about asthma medications, including lack of understanding of the distinction between maintenance and reliever inhalers, suboptimal inhaler technique, and concerns about ICS side effects. Other drivers of poor medication adherence included the high cost of asthma medication, general forgetfulness, and embarrassment over inhaler use in public. Overall, patients' perceived lack of need for asthma medications and medication concerns, in part due to suboptimal knowledge and poor patient-physician communication, emerged as key drivers of poor medication adherence. Optimal asthma care and management should therefore target these barriers through effective patient- and physician-centered strategies.
\end{abstract}

Keywords: Inhaled corticosteroids, over-reliance, patient-physician communication, respiratory tract disease, short-acting $\beta_{2}$-agonist, underuse

\section{Introduction}

Asthma is a chronic inflammatory airway disease that affects approximately 339 million people worldwide. ${ }^{1}$ The Global Initiative for Asthma (GINA) recommends the use of inhaled corticosteroids (ICS) as maintenance therapy for patients with asthma and, until an update in $2019,{ }^{2}$ short-acting $\beta_{2}$-agonists (SABAs) for as-needed relief of asthma symptoms. ${ }^{3}$ However, despite the availability of effective treatment regimens, asthma remains uncontrolled in approximately $50 \%$ of patients who, therefore, remain at risk for potentially serious exacerbations. ${ }^{4,5}$

Poor medication adherence, either intentionally or unintentionally, ${ }^{6}$ is recognized as one of the main reasons for suboptimal asthma management and poor clinical outcomes, ${ }^{7}$ with evidence of widespread ICS underuse across the spectrum of
Correspondence: Suvina Amin AstraZeneca, One Medimmune Way, Gaithersburg, MD 20878, USA $\mathrm{Tel}+$ I 8005655877

Email suvina.amin@astrazeneca.com 
asthma. ${ }^{8,9}$ Such patients often demonstrate over-reliance on SABAs for symptom relief, ${ }^{9}$ which is a concern since excessive use of SABAs may worsen asthma control and increase the risk of fatal or near-fatal asthma events. ${ }^{10-13}$ In parallel, underuse of maintenance ICS may increase the risk of exacerbations because the underlying inflammation is not addressed. ${ }^{14,15}$ The discordance between clinicians' perceptions of patients' medication adherence and actual medication adherence is also problematic, ${ }^{16}$ while the failure to recognize poor medication adherence ${ }^{16}$ or the factors leading to poor adherence $e^{17,18}$ can result in erroneous prescribing patterns and suboptimal asthma outcomes.

To better understand the underlying patient behavior driving medication adherence and patient-centered reasons for inappropriate use of SABAs and ICS, qualitative research may be ideally suited to discover subtleties and nuances from the patients' perspective, which often cannot be gleaned from quantitative research alone. Thus, we sought to identify associated patterns and themes by conducting a targeted literature review of the qualitative evidence on medication adherence in patients with asthma, with specific regard to SABA and ICS use.

\section{Methods}

\section{Data Source}

A targeted literature review was conducted to identify qualitative evidence on adherence to prescribed asthma medications by performing systematic and reproducible literature searches. Searches were conducted in MEDLINE (via PubMed) and EMBASE for articles published in English from January 1, 2012 through February 26, 2018 (Supplementary Table 1). This 6-year search period was chosen to ensure that the data captured would reflect the current status of medication adherence in the asthma treatment landscape.

\section{Study Selection}

Articles were selected through 2 levels of screening. At the abstract level, PICOS (population, intervention, comparison, outcome, and study design) criteria outlining the characteristics of studies to be selected for further review were applied (Table 1). Articles that presented observational and clinical study data evaluating medication adherence and associated outcomes in patients ( $\geq 12$ years old) with asthma receiving licensed treatments, and from any geographical region, were included. At the full-text level,
Table I PICOS Criteria for Study Selection

\begin{tabular}{|l|l|}
\hline Criteria & Inclusion Criteria \\
\hline Population(s) & Persons aged $\geq 12$ years with asthma \\
\hline $\begin{array}{l}\text { Interventions/ } \\
\text { comparators }\end{array}$ & $\begin{array}{l}\text { Licensed treatments and/or complementary and } \\
\text { alternative medicine }\end{array}$ \\
\hline Outcomes & $\begin{array}{l}\text { Medication initiation, implementation, and } \\
\text { discontinuation }\end{array}$ \\
\hline Study design & $\begin{array}{l}\text { Qualitative research (prospective and } \\
\text { retrospective studies, } \\
\text { cross-sectional and longitudinal studies, } \\
\text { systematic literature reviews, and clinical trials) }\end{array}$ \\
\hline Other & English language, any geographical region \\
\hline
\end{tabular}

Abbreviation: PICOS, population, intervention, comparison, outcome, and study design.

a senior investigator determined which articles provided the best evidence for inclusion.

In addition, 2 independent researchers evaluated the articles using the National Institute for Health and Care Excellence (NICE) quality appraisal checklist - qualitative studies, ${ }^{19}$ according to which articles were scored on the basis of their theoretical approach (whether the qualitative design was appropriate), study design, data collection method, trustworthiness, analysis, and ethics. Based on the checklist, articles were rated as "good," "fair," or "mixed."

\section{Data Analysis}

Data extraction of the studies selected for the targeted review was performed using the data extraction template designed in Microsoft Word $^{\circledR}$. Data were captured from each included study by a single investigator and $50 \%$ of the data were validated by checking for accuracy and consistency in reporting by a second, more senior researcher. The extracted data were analyzed using a thematic analysis. ${ }^{20-22}$ This involved initial reading and rereading of the extracted data to identify themes relating to initiation, implementation (the quality of regimen execution), and discontinuation of asthma treatment regimens from the patient perspective, caregiver perspective (if available in the abstracted articles), or physician perspective (if available in the abstracted articles). If multiple perspectives were available (patient, caregiver, and physician), the results were triangulated with one another to identify similarities and differences. Five steps of the thematic analysis were executed: in-depth reading of each article, abstraction of the 
qualitative findings, initial coding of the abstracted qualitative findings, comparison and contrast of themes across the abstracted studies for further refinement, and final synthesis of data-driven themes. The abstracted data were initially assigned discrete conceptual labels that would break down the abstracted qualitative findings into descriptive qualitative themes. For example, findings that patients considered asthma medication as a pro re nata (prn) therapy may be initially given a "prn" code. As codes are added through iterative review of the abstracted articles, a final coding schema would emerge. The analysis was directed by the available data, whereby themes were developed through constant comparison of the similarities and differences in the abstracted qualitative data and both supportive and disconfirming evidence of the themes was identified.

\section{Results}

\section{Targeted Search Results}

Of the 254 citations identified in MEDLINE (via PubMed) and EMBASE, 21 relevant articles were included (Figure 1, Supplementary Tables 2 and 3 ). Of these, 14 were sourced from database searches. Additionally, 8 potential articles were identified from the reference lists of included articles. After undergoing screening for eligibility, 1 article was subsequently deemed ineligible and 7 were included in the analysis. A quality assessment was performed per the NICE appraisal checklist ${ }^{19}$ on all included articles. Overall, 9 studies $^{23-31}$ were rated as "good," 11 studies ${ }^{18,32-41}$ were rated as "fair," and 1 study ${ }^{42}$ was rated as "mixed" by 2 independent researchers with good agreement.

Characteristics of the included studies are summarized in Supplementary Table 4 . The studies were performed across 7 countries: United States $(n=9)$, Canada and Australia $(n=3$ each), Sweden and the United Kingdom ( $\mathrm{n}=2$ each), and Germany and the Netherlands ( $\mathrm{n}=1$ each). Most studies $(57 \%[n=12])$ focused on adults, while $19 \%(n=4)$ sampled adolescents and adults and 24\% $(n=5)$ sampled adolescents only. Study methods varied, involving one-on-one interviews $(57 \%[n=12])$, qualitative focus groups $(38 \%[n=8])$, and open-ended questions within a survey $(5 \%[n=1])$.

\section{Drivers of Poor Medication Adherence in Asthma}

Thematic analyses of the included studies identified several major themes on barriers to asthma medication adherence across the extracted studies. Representative patient sentiments are captured in quotes with key themes provided in Table 2 and discussed further below.

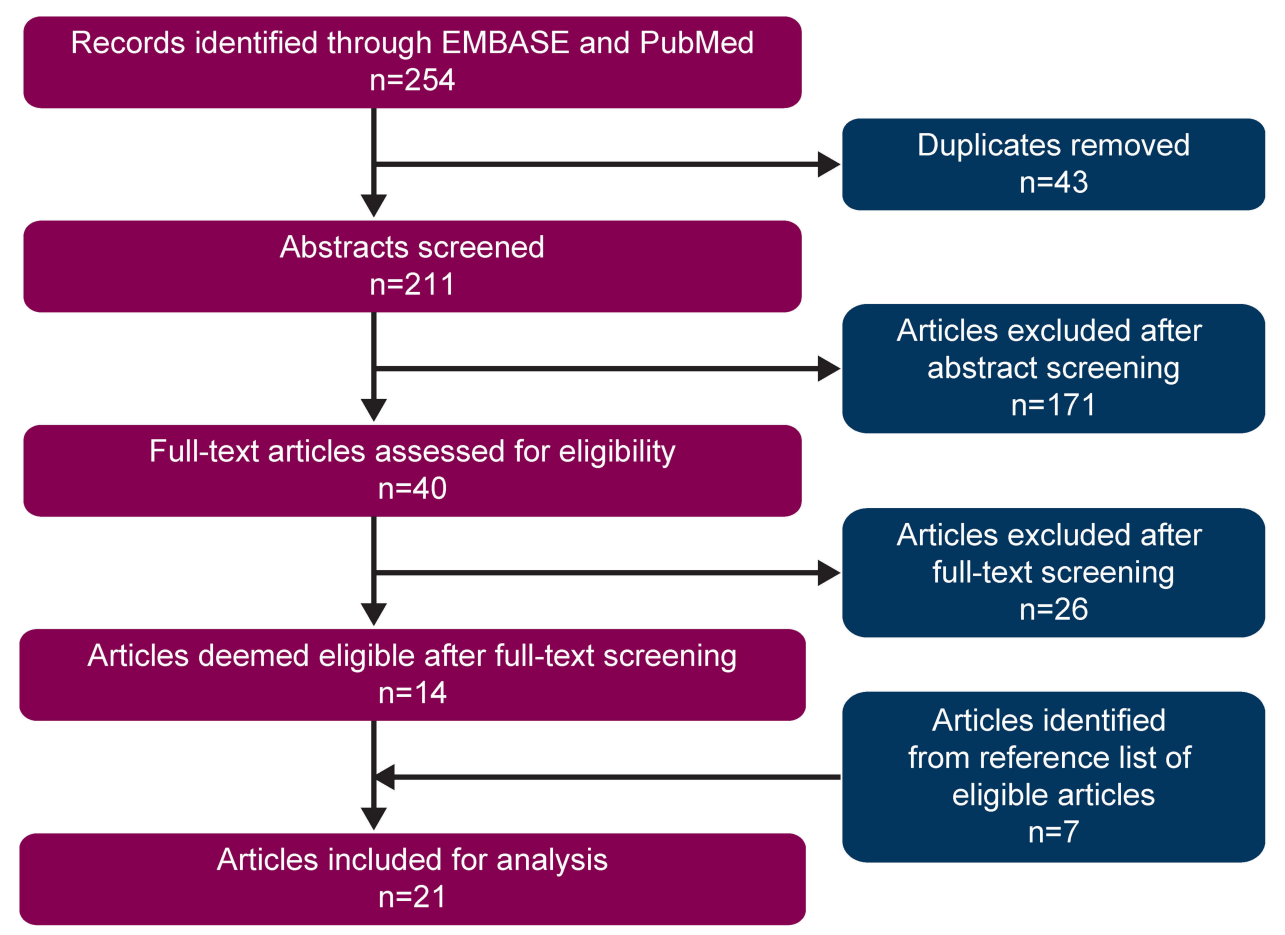

Figure I Summary of study selection for analysis. 
Table 2 Representative Statements from Patients Highlighting Key Drivers Affecting Medication Adherence in Asthma

\begin{tabular}{|c|c|}
\hline Theme & Quote \\
\hline $\begin{array}{l}\text { Doubts about the accuracy of asthma } \\
\text { diagnosis }\end{array}$ & $\begin{array}{l}\text { "Not every GP has pulmonary function test equipment and (even when he possesses the equipment) } \\
\text { can make accurate diagnoses" } \\
\text { "... maybe even people in general sometimes have trouble breathing ... I don't know what's } \\
\text { normal"32 }\end{array}$ \\
\hline Daily life is unaffected by asthma & $\begin{array}{l}\text { "I don't use it at all ... right after I come from the doctor's, I take it for } 2 \text { to } 3 \text { days and then I just } \\
\text { forget. It is not that I don't want to take it, it is that I forget to take it ... if I had more symptoms, } \\
\text { then I would take it"25 } \\
\text { "I think it [diabetes] makes me lose sight of my asthma until something, you know, until I can't } \\
\text { breathe or it's hot out or something"28 } \\
\text { "Don't need to take any medication until the pollen season comes. Maybe when it's really cold"38 }\end{array}$ \\
\hline Patient-physician communication & $\begin{array}{l}\text { "When I go to my appointment, they try to rush, get you in there, } \\
\text { rush you out, get you some stuff, take this, do this"29 } \\
\text { "We never actually sat down and made a plan"29 }\end{array}$ \\
\hline $\begin{array}{l}\text { Suboptimal knowledge of reliever and } \\
\text { maintenance medications }\end{array}$ & "I was like supposed to take so many puffs a day, and I over use it"18 \\
\hline Suboptimal inhaler technique & "Have you taken or inhaled the full dose, or not? You never know"34 \\
\hline Perceived concerns about side effects & $\begin{array}{l}\text { "I had to take steroids, which has made me gain weight, which has sort of kept me from exercising"40 } \\
\text { "... when I take my medicine, sometimes I still get sick. When I don't take my medicine, I don't get } \\
\text { sick. I really don't see where it comes in handy, but I guess if the doctor says I need it, I need it"25 }\end{array}$ \\
\hline Stigma of inhaler use & $\begin{array}{l}\text { "I hate feeling like I'm different. I have a problem when it comes to that and I hold off on my } \\
\text { medicine. As you get older, you care what people think more. So I try to hold [asthma medication] } \\
\text { off and be cool" } 29\end{array}$ \\
\hline Perceived medication affordability & $\begin{array}{l}\text { "My physician told me to take my medication in the mornings and in the evenings, but I take it every } \\
\text { two days because that's a lot of money" }\end{array}$ \\
\hline
\end{tabular}

Abbreviation: GP, general practitioner.

\section{Doubts About the Accuracy of Asthma Diagnosis}

Medication use typically begins with a prescription of medication following diagnosis of the disease; however, an asthma diagnosis did not always translate into regular medication use, with patients having doubts about the accuracy of their diagnosis.

Patients often questioned their diagnosis due to lack of a clear diagnosis from their physician, denial on their part, or distrust of the medical community. ${ }^{18,24,32-35,42}$

Lingner et $\mathrm{al}^{33}$ engaged adult patients (20-77 years old) in focus group discussions and noted that patients reported a lack of consensus across physicians (primary care vs specialists) on the diagnosis of asthma. Murdoch et $\mathrm{al}^{42}$ conducted face-toface interviews with patients (17-80 years old) and noted that patients believed there is uncertainty in medical knowledge. Interestingly, for many patients, doubts about the accuracy of their diagnosis may have been based on them not wanting to acknowledge that they had a chronic disease requiring longterm (potentially life-long) treatment. ${ }^{18,35,42}$
Skepticism about the accuracy of asthma diagnosis was harbored by patients across age groups. McDonald et $\mathrm{al}^{24}$ reported that the absence of a diagnosis, a protracted diagnosis, or a missed diagnosis was a concern for many older patients ( $\geq 55$ years old), with some patients expressing frustration with repeated attempts to confirm their diagnosis. Interviewed young adults (all aged 22 years) also expressed doubts about the accuracy of their diagnosis, arguing that asthma symptoms may be experienced by all people. ${ }^{32}$

\section{Daily Life Was Unaffected by Asthma}

The perceived lack of impact of asthma on daily life may also contribute to patients' uncertainty about the accuracy of their diagnosis, such that adults and adolescents develop a "no symptoms, no asthma" outlook about the disease.

Indeed, due to the episodic nature of the disease and related symptoms, many patients did not always consider asymptomatic asthma as an "illness."25,30,38 Consequently, they discontinued their asthma medication when they felt 
well; however, when exacerbations occurred or symptoms became pronounced, patients reverted to their asthma medication. $^{24,28,30-35}$ This took the form of overuse of reliever inhalers, ${ }^{39}$ as-needed use of maintenance medication, ${ }^{24,26,30,35}$ or both. ${ }^{31,32}$ Despite having experienced asthma attacks or exacerbations, many patients felt that their daily life and daily functioning were relatively unaffected by asthma. ${ }^{32}$ Patients used permissive adherence reasoning by "acting on the spur of symptoms" and justified such behavior because they felt that "asthma was playing out of earshot." Unstructured medication use was also observed, wherein the maintenance inhaler was not used consistently, with an increase in asthma symptoms triggering the intake of asthma medication. ${ }^{32}$ Similarly, Peláez et $\mathrm{al}^{35}$ described asthma as "a disease experienced along a continuum," where symptom-free intervals led to patients neglecting the importance of daily preventive medication. ${ }^{35}$ McDonald et $\mathrm{al}^{24}$ described intentional nonadherence whereby treatment was self-titrated according to patients' perceived needs and symptoms. For instance, a patient described using their maintenance inhaler only when symptoms worsened, instead of taking it twice daily as prescribed. ${ }^{24}$ Among adolescents, it emerged that many based adherence on their belief of how "serious" or "real" their asthma was; as such, some patients did not think they had "real" asthma and, therefore, need not take daily maintenance medication unlike others with more "serious" asthma. ${ }^{30}$ Similarly, even among adults with uncontrolled asthma, many believed that they were prescribed more ICS than necessary for their level of asthma severity and were thus more likely to underuse ICS and overuse SABAs. ${ }^{31}$

Unsurprisingly, asthma was also given a lower priority compared with other chronic diseases. Patients deprioritized asthma symptoms, perceiving asthma as less severe compared with other chronic diseases, such as diabetes, heart disease, and arthritis. ${ }^{28,32}$ Janevic et $\mathrm{al}^{28}$ reported that less than half of patients considered asthma as their "main health problem," with patients describing how asthma took a "backseat" to conditions they considered more worrisome. This was especially observed during asymptomatic periods of asthma.

\section{Patient-Physician Communication}

While medication adherence is considered primarily the domain of the patient, the relationship between the patient and physician exerts a large influence on whether the patient will appropriately use the medication as directed. Poor communication between the patient and physician can further aggravate patients' confusion about their diagnosis, and this was reported as a significant driver of poor medication adherence.

Our findings revealed that lack of clear communication, discontent with the physician's diagnosis and choice of medication, and feeling that the patient was being ignored were recurring themes. ${ }^{24,29-31,33,36}$ Peláez et $\mathrm{al}^{36}$ conducted faceto-face interviews with adults, adolescents, and parents of children who listed certain patient-physician issues, such as lack of a clear diagnosis from the physician, lack of a formal or objective assessment of disease severity, insufficient explanation of asthma and its management, and lack of a patient-centered approach by the physician, as barriers to long-term ICS use. Many patients complained of a lack of an objective assessment of disease severity, due to which the severity of their disease remained unclear to them, leading to confusion in ascertaining the true impact of treatment. ${ }^{36}$

Speck et $\mathrm{al}^{29}$ conducted focus group discussions with African American adults, many of whom felt frustrated that physicians did not take the time to explain asthma management and simply just prescribed the drugs. Others complained of a lack of an adequate asthma management (action) plan. ${ }^{29}$ In the study by Lingner et $\mathrm{al}^{33}$ patients were concerned about a lack of consensus among different physicians regarding the best treatment for them. Patients found disagreements on appropriate medication or the lack of communication between generalists and specialists problematic. Consistent with patients from other studies, they wished to be involved in decisions regarding the most appropriate therapy for them; however, none recalled a shared decision-making process. Patients also wanted their providers to treat them as wellinformed individuals and discuss with them all available therapeutic options. ${ }^{33}$ Poor patient-physician communication directly influenced medication adherence as revealed in openended qualitative interviews with urban adults where patients complained that their healthcare providers did not listen to them and, as a result, were more likely to ignore their provider's recommendations. ${ }^{31}$

\section{Suboptimal Patient Knowledge}

Inadequate communication between the patient and physician can further undermine medication adherence by compromising patients' understanding of the disease and the importance of medication adherence. Due to suboptimal knowledge, patients may be unable to distinguish between maintenance and reliever medications, have incorrect inhaler technique, and have concerns about the efficacy of medications and potential side effects. 
Difference Between Maintenance and Reliever Medications Many articles noted patients' struggles with understanding the difference between maintenance and reliever medications, a finding that was observed across age groups. ${ }^{18,26,30,31,34,37,39}$

Mowrer et al ${ }^{18}$ observed that despite providers feeling that they had clarified the differences between medication types, many patients with asthma used reliever and maintenance medications interchangeably, while others only used the medication that appeared to work for them. Many adolescents reported confusion regarding their medications and failure to understand the need for maintenance medications, resulting in their improper use. ${ }^{26,39}$ For instance, a teenage patient reported using a reliever inhaler on the days he forgot to take his maintenance medication, regardless of symptoms experienced. ${ }^{39}$ Another adolescent reported regular use of a reliever and use of a maintenance inhaler only when symptoms worsened, as the patient believed it was "quick-acting." ${ }^{26}$ George et $\mathrm{al}^{31}$ reported that urban adult patients were over-reliant on SABAs and used ICS only when symptomatic, whereas focus groups with rural adolescents revealed a lack of awareness and understanding of asthma symptoms and what asthma control meant, with most patients reporting reliever inhaler use $>2$ times a week ${ }^{37}$ (such use would not be consistent with controlled asthma).

Physicians have expressed agreement with these observations. According to Peláez et al, ${ }^{34}$ many believed that patients did not understand the benefits of daily maintenance medication, and that short-acting reliever medication was more likely to be used because of the immediacy of symptom relief.

\section{Inhaler Technique}

Difficulty in using inhalers and inadequate practice and/or demonstration of inhaler use by physicians were frequently reported. ${ }^{18,23,33,34}$ Many patients had a limited understanding of how to properly use their inhalers. ${ }^{18}$ In the focus group discussions by Mowrer et al, ${ }^{18}$ many patients realized that they were receiving only partial doses due to faulty inhaler technique. Davis et $\mathrm{al}^{23}$ highlighted the complexity involved in correctly using inhalers among patients with intellectual disabilities, with several reporting difficulty using inhaler devices in the past. Moreover, while many patients were able to describe what a spacer looked like, they reported using it inconsistently. ${ }^{23}$ Lingner et $\mathrm{al}^{33}$ reported that patients believed if medication was indeed necessary, drug use should be simplified as much as possible. Notably, some patients discussed the use of a combined, individualized and symptom-driven use of single-agent drugs with their physicians. ${ }^{33}$

Both patients and physicians noted that some inhalers were not "user-friendly." 34 Patients felt that this was because it was hard to discern whether the inhaler was being used correctly and whether they were receiving the full dose, and physicians acknowledged that using an inhaler required more technical knowledge than taking a pill. ${ }^{34}$ In addition, patients also felt that physicians did not demonstrate inhaler use $\mathrm{s}^{33}$ and wanted physicians to take time to help them practice using an inhaler.

\section{Perceived Lack of Efficacy and Fear of Side Effects}

For some patients, the underlying reasons for minimizing consistent use of asthma maintenance medications were perceived lack of efficacy ${ }^{24,25}$ and perceived dangers associated with medication use (eg, fear of side effects and of addiction or dependence). ${ }^{25,35,42}$ Face-to-face interviews with older adolescents revealed that, for many, the experience of or concerns about side effects led to poor medication adherence. $^{25}$ Specific fears or negative beliefs about ICS use were also expressed. ${ }^{31,33,34}$ These fears were related to drug dependency ${ }^{33}$ and perceived side effects, such as weight gain, ${ }^{31}$ muscle pain, dizziness, dry throat, ${ }^{34}$ and "developing a moon face." ${ }^{33}$ Physicians believed that some concerns regarding side effects were, at times, valid, but could also be attributable to irrational or erroneous beliefs. ${ }^{34}$

\section{Miscellaneous Barriers to Medication Adherence}

In addition to the themes described above, several other patient-centered barriers to adherence with inhaled treatment were also noted. Unintentional non-adherence was mainly attributed to general forgetfulness in both adults and adolescents. $^{23,25,26,30,31,36,38,39,41}$ Many patients either experienced difficulty in incorporating their regular asthma medication into their daily routine $\mathrm{e}^{23}$ or found establishing a daily routine challenging. ${ }^{25,30,38,39}$ Many adolescents and adults also reported feeling embarrassed to use inhalers in public. $^{23,29,30,34}$ Patients reported using alternatives to ICS, such as relaxation, rest, and drinking water, to manage their asthma symptoms as they were skeptical that asthma could be controlled. $^{31}$

Healthcare systems can also impose barriers to medication adherence by limiting a patient's access to appropriate therapy. Indeed, the high cost of some asthma medications was listed by both patients ${ }^{18,29,33,34,38}$ and physicians ${ }^{34}$ as 
negatively affecting medication adherence, with some patients reporting rationing their medications to reduce expenses. ${ }^{18,34}$

\section{Discussion}

This targeted literature review of qualitative studies aimed to improve understanding of the underlying reasons for poor medication adherence in asthma from the patient's perspective. Several overarching themes related to poor medication adherence emerged across the studies. The drivers of poor medication adherence encompassed patient-centered factors, physician-centered factors, and factors related to the healthcare system, which were interconnected and further drove the cycle of non-adherence.

We found that patients with asthma tended to express doubts about the accuracy of their diagnosis, ${ }^{18,24,32-35}$ in part because they felt that their daily life was not substantially impacted by asthma. $^{24,25,27-30,32,33,36,38,42}$ This was compounded by poor patient-physician communication, ${ }^{24,29-31,33,35,36}$ which contributed to certain erroneous beliefs and suboptimal knowledge about asthma medications. For instance, patients often failed to understand the differences between maintenance and reliever inhalers, ${ }^{18,26,30,34,37,39}$ had suboptimal inhaler technique, ${ }^{18,23,33,34}$ and had concerns about the side effects of ICS. ${ }^{25,26,33,34}$ Other drivers of poor medication adherence included the high cost of asthma medication ${ }^{18,29,33,34,38}$ and general forgetfulness, ${ }^{23,31,36}$ especially among young adults and adolescents, ${ }^{25,26,30,38,39,41}$ and embarrassment about using inhalers in public. $23,29,30,34$

Several of these aspects were recognized as general drivers that typically affect medication adherence in chronic illnesses; however, we also identified patient-centered drivers that were unique to asthma (Figure 2). Among the general drivers, poor communication between patients and physicians, including a lack of a shared decision-making process; inadequate understanding of the disease; and high medication costs have been previously reported to affect medication adherence in chronic illnesses. ${ }^{43-45}$ Our study findings highlighted patient-physician communication to be crucial to medication adherence in the management of asthma. Medical visits provide a key opportunity to influence a patient's intention to take daily ICS ${ }^{46}$ however, it was found that many patients described feeling rushed or unheard or that they were "just another number."24,29

For chronic conditions, such as cardiovascular disorders, when patients feel better, they are more likely to stop taking their medication. ${ }^{43,44}$ It is thus a challenge to treat conditions in which the symptoms may be relatively infrequent, as is the case for a variable disease such as asthma. We found that many patients felt that asthma did not affect their daily life, leading to a lack of adherence to daily inhaled therapy. ${ }^{25,29,30,38}$ Poor adherence to medication is also common in chronic illnesses when a tangible benefit is not immediately evident for a particular treatment. ${ }^{45,47}$

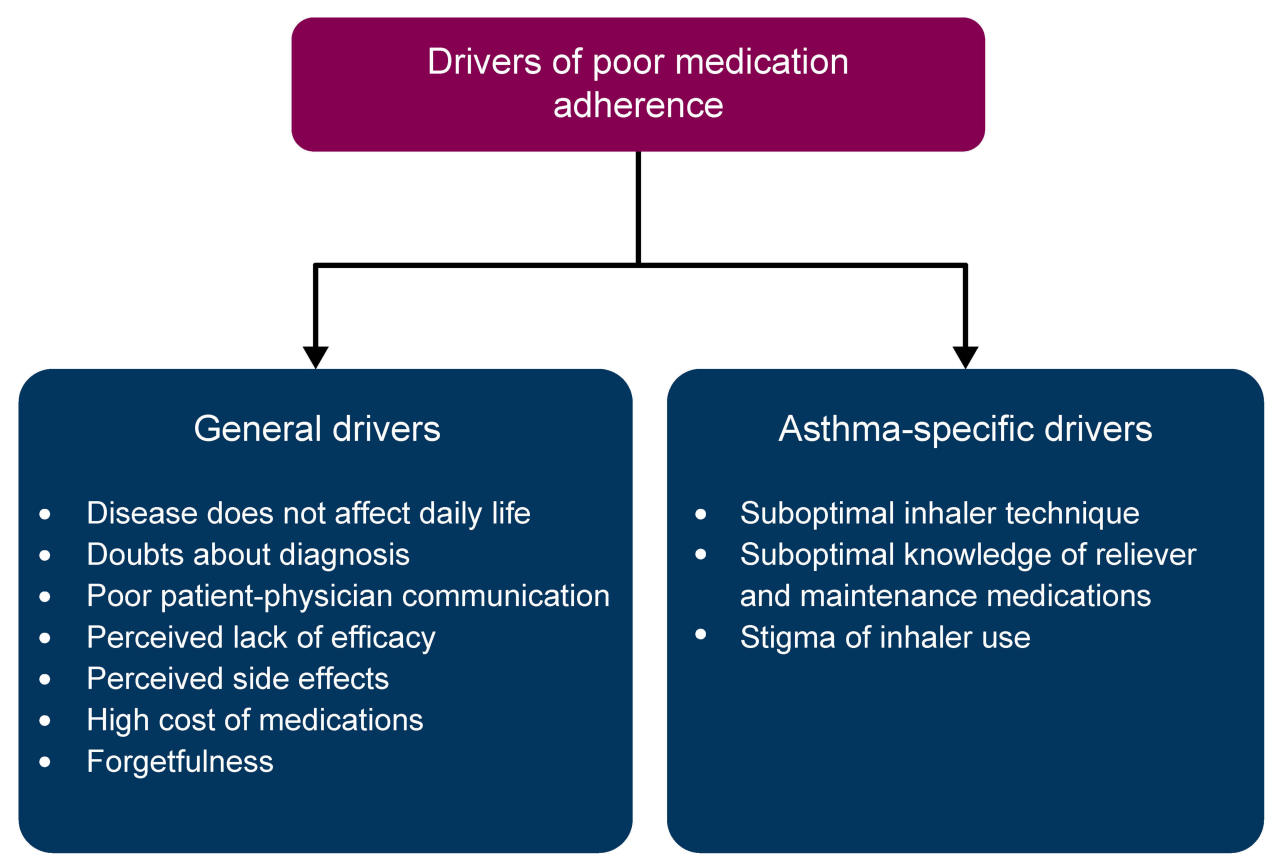

Figure 2 Drivers of medication adherence in asthma derived from qualitative literature. 
Not surprisingly, our findings revealed that patients questioned the need for daily maintenance medication as they did not understand the benefits of daily maintenance therapy for an episodic condition such as asthma. ${ }^{25,27,31}$ Similar to the findings of the INSPIRE study, ${ }^{9}$ we found that many patients took maintenance medication as needed or altered their medication dose according to their perceived disease burden. ${ }^{18,26,31,33}$ Due to the long-term use of medication in chronic illnesses, a fear of side effects can also compromise medication adherence. ${ }^{43,44}$ We observed that both adolescent and adult patients reported medication concerns, specifically a fear of side effects from ICS use. ${ }^{23,25,31,33,40}$ Consistent with our findings, multiple studies have reported patients' concerns regarding the prescription of ICS, ${ }^{17,48,49}$ which have translated into ICS underuse, including symptom-directed usage and improved adherence only in the time up to and after an exacerbation. ${ }^{8,17}$

Suboptimal health literacy among patients contributes to a lack of understanding of the disease and is a common reason for poor medication adherence. ${ }^{43,45}$ This is especially problematic in asthma due to the often complex treatment regimens and is the basis of several asthma-specific barriers to medication adherence. Patients lacked an understanding of the difference between reliever and maintenance medications. ${ }^{18,24,26}$ They did not recognize the need for daily ICS therapy and reported overusing SABAs because they offered rapid relief. $^{31,32,39}$ Furthermore, variations in the terminologies used for reliever and maintenance medications can be a source of confusion. Multiple terms are used for SABA therapy, such as "rescue" and "reliever," and for ICS therapy, such as "maintenance," "preventive," and "controller," underscoring the need to standardize terminology. In addition, incorrect or suboptimal inhaler technique led to non-adherence, as patients found it challenging to use the inhaler correctly and to identify whether they had received the full dose of medication. ${ }^{23,33,34}$ Interestingly, while patients had suboptimal knowledge about their medication, ${ }^{18,24,26}$ they were still interested in a shared decision-making process and indicated that they did not want to simply "trust" their physician. ${ }^{33}$ This gap in communication between patients and physicians highlights the need for improvement in the patient-physician relationship and the importance of empowering patients through better communication with their physicians so that they are motivated to adhere to their medication. Indeed, a shared decision-making process between physicians and patients, accommodating patient goals and preferences, led to increased medication adherence and improved clinical outcomes compared with an approach where physicians made decisions independently. ${ }^{50}$ In addition, self-management involving personalized written action plans with regular physician review can be a tool to improve physician-patient communication and patient empowerment, ${ }^{51}$ and has been associated with improved clinical outcomes such as fewer emergency department visits and hospital admissions and better lung function. ${ }^{52}$

Taken together, our findings on patient drivers of poor medication adherence are consistent with the current understanding of this issue and highlight the challenges associated with improving adherence. However, most drivers for poor medication adherence were deliberate in nature and may therefore be modifiable through strategies involving patients, physicians, and the healthcare system. Patient-centered interventions with proven effectiveness include patient engagement and education initiatives, such as routine counseling and training for patients to better understand their condition, ${ }^{53}$ training on inhaler technique, ${ }^{54}$ and the introduction of programs rewarding patients for optimal adherence and outcomes. ${ }^{55}$ In addition, the use of digital tools, such as electronic reminders or trackers, and "smart" inhaler technology to support asthma management can facilitate better adherence. ${ }^{56-58}$ Physician-centered interventions including initiatives aimed at encouraging nurses, pharmacists, and physicians to provide integrative and supportive follow-up care may also be necessary to address the gap in communication between patients and physicians. Physician education might also focus on inhaler technique training, as physicians themselves may be frequently unable to use inhalers correctly ${ }^{59-61}$ and, thus, are unlikely to be able to demonstrate their appropriate use to patients. Other strategies include the use of objective diagnostic tests ${ }^{3}$ such as spirometry or peak expiratory flow measurements to confirm diagnosis in order to avoid ambiguity and improve communication between physicians to avoid conflicting diagnoses.

Healthcare-centered interventions, such as simplification of the asthma regimen by involving the use of single-inhaler therapy instead of multiple inhalers, may also help improve medication adherence in asthma. ${ }^{62-65}$ Furthermore, one of the recurring themes in our study — consistent with reported paradoxes in the treatment of asthma ${ }^{66,67}$ — was the use of medication only when symptoms occur (ie, short-acting reliever alone) and avoidance of treatment perceived to be unnecessary (ie, ICS maintenance). Unlike ICS, SABAs lack any inherent anti-inflammatory properties ${ }^{68}$ and thus do not treat the underlying inflammation of asthma. In addition, SABA overuse $(\geq 3$ canisters/year) is associated with an increased risk of severe exacerbations. ${ }^{2,69}$ GINA recommendations also acknowledge 
that adherence to ICS is poor in patients with mild asthma, exposing them to the risks of SABA-only treatment. ${ }^{2}$ Thus, updated GINA 2019 recommendations no longer recommend starting with SABA-only treatment, and instead indicate asneeded, low-dose ICS-formoterol as the joint preferred reliever/controller at GINA Steps $1-2{ }^{2}$

To our knowledge, this is the first targeted literature review to provide a comprehensive qualitative report of the drivers of poor medication adherence in asthma from the patient's perspective, which employed a quality assessment analysis, included evidence collected from various qualitative methodologies, covered 7 geographical regions, and comprised patients across age groups. However, certain limitations should be acknowledged. Clear and equivocal contextualization of the results of qualitative research can be problematic for several reasons. For instance, precise methods of the qualitative analysis were not always clearly specified in the studies included; differences in sampling strategies could have affected the representativeness of the obtained samples and the differential use of data from one-on-one interviews vs focus groups could have affected the breadth and depth of the obtained data. Finally, while extensive literature searches were conducted using PubMed and EMBASE, health-related qualitative research databases such as CINAHL and PsycINFO were not used, which could have led to article omissions.

\section{Conclusions}

Medication adherence is a challenge in a chronic illness such as asthma. We identified key factors, such as patients' low perceived need for asthma medications, inadequate communication between patients and physicians, perceived medication concerns, and suboptimal patient knowledge including incorrect inhaler technique, driving poor adherence to asthma medication, which manifests as underuse of ICS and over-reliance on SABAs. To recognize the full benefits of current therapies, optimal asthma care needs to target these patient- and physician-centered barriers through effective multifactorial interventions.

\section{Data Sharing Statement}

Data underlying the findings described in this manuscript may be obtained in accordance with AstraZeneca's data sharing policy described at https://astrazenecagrouptrials. pharmacm.com/ST/Submission/Disclosure.

\section{Acknowledgments}

Medical writing and editorial support was provided by Michelle Rebello, PhD, of Cactus Communications (Mumbai, India), which was funded by AstraZeneca in accordance with Good Publication Practice (GPP3) guidelines (http://www.ismpp.org/gpp3). These findings have been previously presented at the ISPOR Europe Conference, 10-14 November 2018, Barcelona, Spain.

\section{Author Contributions}

All authors contributed to data analysis, drafting and revising the article, gave final approval of the version to be published, and agree to be accountable for all aspects of the work.

\section{Funding}

This study was funded by AstraZeneca. The sponsor was involved in the design of the study and was allowed to review the draft before submission.

\section{Disclosure}

Suvina Amin, Mena Soliman, and Claudia Cabrera are employees of AstraZeneca. Andrew McIvor has received honoraria for attending advisory boards, providing continuing medical education, and taking part in clinical trials as an investigator from AstraZeneca, Boehringer Ingelheim, GlaxoSmithKline, Pfizer, Merck, and Novartis. Andrew Cave has received research funding from AstraZeneca, Grifols, and GlaxoSmithKline and honoraria from GlaxoSmithKline, AstraZeneca, Sanofi, and Boehringer Ingelheim. The authors report no other conflicts of interest in this work.

\section{References}

1. The Global Asthma Network. Global asthma report. 2018. Available from: http://www.globalasthmareport.org. Accessed August 19, 2019.

2. Global Initiative for Asthma (GINA). Global strategy for asthma management and prevention. 2019. Available from: https://ginasthma. org/wp-content/uploads/2019/06/GINA-2019-main-report-June-2019wms.pdf. Accessed August 19, 2019.

3. Global Initiative for Asthma (GINA). Global strategy for asthma management and prevention. 2018. Available from: https://ginasthma. org/wp-content/uploads/2019/01/2018-GINA.pdf. Accessed August 19, 2019.

4. Demoly P, Annunziata K, Gubba E, Adamek L. Repeated cross-sectional survey of patient-reported asthma control in Europe in the past 5 years. Eur Respir J. 2012;21:66-74. doi:10.1183/ 09059180.00008111

5. Price D, Fletcher M, Van Der Molen T. Asthma control and management in 8000 European patients: the REcognise Asthma and LInk to Symptoms and Experience (REALISE) survey. NPJ Prim Care Respir Med. 2014;24:14009. doi:10.1038/npjpcrm.2014.9 
6. van Boven JF, Trappenburg JC, van der Molen T, Chavannes NH. Towards tailored and targeted adherence assessment to optimise asthma management. NPJ Prim Care Respir Med. 2015;25:15046. doi:10.1038/npjpcrm.2015.46

7. Gamble J, Stevenson M, McClean E, Heaney LG. The prevalence of nonadherence in difficult asthma. Am J Respir Crit Care. 2009;180 (9):817-822. doi:10.1164/rccm.200902-0166OC

8. Bårnes CB, Ulrik CS. Asthma and adherence to inhaled corticosteroids: current status and future perspectives. Respir Care. 2015;60 (3):455-468. doi:10.4187/respcare.03200

9. Partridge MR, van der Molen T, Myrseth SE, Busse WW. Attitudes and actions of asthma patients on regular maintenance therapy: the INSPIRE study. BMC Pulm Med. 2006;6:13. doi:10.1186/1471-2466-6-13

10. Spitzer WO, Suissa S, Ernst P, et al. The use of beta-agonists and the risk of death and near death from asthma. $N$ Engl J Med. 1992;326 (8):501-506. doi:10.1056/NEJM199202203260801

11. Salpeter SR, Ormiston TM, Salpeter EE. Meta-analysis: respiratory tolerance to regular beta 2-agonist use in patients with asthma. Ann Intern Med. 2004;140(10):802-813. doi:10.7326/0003-4819-140-10-20040518000010

12. Suissa S, Blais L, Ernst P. Patterns of increasing beta-agonist use and the risk of fatal or near-fatal asthma. Eur Respir J. 1994;7(9):1602-1609. doi:10.1183/09031936.94.07091602

13. Suissa S, Ernst P, Boivin JF, et al. A cohort analysis of excess mortality in asthma and the use of inhaled beta-agonists. Am J Respir Crit Care. 1994;149(3):604-610. doi:10.1164/ajrccm.149.3.8118625

14. Engelkes M, Janssens HM, de Jongste JC, Sturkenboom MC, Verhamme KM. Medication adherence and the risk of severe asthma exacerbations: a systematic review. Eur Respir J. 2015;45(2):396-407. doi:10.1183/09031936.00075614

15. Williams LK, Peterson EL, Wells K, et al. Quantifying the proportion of severe asthma exacerbations attributable to inhaled corticosteroid nonadherence. J Allergy Clin Immunol. 2011;128(6):1185-1191. e1182. doi:10.1016/j.jaci.2011.09.011

16. Sapir T, Moreo KF, Greene LS, et al. Assessing patient and provider perceptions of factors associated with patient engagement in asthma care. Ann Am Thorac Soc. 2017;14(5):659-666. doi:10.1513/ AnnalsATS.201608-602OC

17. Cooper V, Metcalf L, Versnel J, Upton J, Walker S, Horne R. Patient-reported side effects, concerns and adherence to corticosteroid treatment for asthma, and comparison with physician estimates of side-effect prevalence: a UK-wide, cross-sectional study. NPJ Prim Care Respir Med. 2015;25:15026. doi:10.1038/ npjpcrm.2015.26

18. Mowrer JL, Tapp H, Ludden T, et al. Patients' and providers' perceptions of asthma and asthma care: a qualitative study. J Asthma. 2015;52(9):949-956. doi:10.3109/02770903.2015.1010731

19. National Institute for Health and Care Excellence. Appendix H Quality appraisal checklist - qualitative studies. 2012. Available from: https://www.nice.org.uk/process/pmg4/chapter/appendix-h-qual ity-appraisal-checklist-qualitative-studies. Accessed June 26, 2019 ..

20. Dixon-Woods M, Agarwal S, Jones D, Young B, Sutton A. Synthesising qualitative and quantitative evidence: a review of possible methods. J Health Serv Res Policy. 2005;10(1):45-53. doi: $10.1177 / 135581960501000110$

21. Thomas J, Harden A. Methods for the thematic synthesis of qualitative research in systematic reviews. BMC Med Res Methodol. 2008;8:45. doi:10.1186/1471-2288-8-45

22. Braun V, Clarke V. Using thematic analysis in psychology. Qual Res Psychol. 2006;3:77-101. doi:10.1191/1478088706qp063oa

23. Davis SR, Durvasula S, Merhi D, Young PM, Traini D, Bosnic Anticevich SZ. Knowledge that people with intellectual disabilities have of their inhaled asthma medications: messages for pharmacists. Int J Clin Pharm. 2016;38(1):135-143. doi:10.1007/s11096-0150217-x
24. McDonald VM, Higgins I, Gibson PG. Insight into older peoples' healthcare experiences with managing COPD, asthma, and asthmaCOPD overlap. J Asthma. 2013;50(5):497-504. doi:10.3109/ 02770903.2013 .790415

25. Naimi DR, Freedman TG, Ginsburg KR, Bogen D, Rand CS, Apter AJ. Adolescents and asthma: why bother with our meds? $J$ Allergy Clin Immunol. 2009;123(6):1335-1341. doi:10.1016/j. jaci.2009.02.022

26. Edgecombe K, Latter S, Peters S, Roberts G. Health experiences of adolescents with uncontrolled severe asthma. Arch Dis Child. 2010;95:985-991. doi:10.1136/adc.2009.171579

27. Foster JM, Reddel HK, Usherwood T, Sawyer SM, Smith L. Patientperceived acceptability and behaviour change benefits of inhaler reminders and adherence feedback: a qualitative study. Respir Med. 2017;129:39-45. doi:10.1016/j.rmed.2017.05.013

28. Janevic MR, Ellis KR, Sanders GM, Nelson BW, Clark NM. Selfmanagement of multiple chronic conditions among African American women with asthma: a qualitative study. $J$ Asthma. 2014;51 (3):243-252. doi:10.3109/02770903.2013.860166

29. Speck AL, Nelson B, Jefferson SO, Baptist AP. Young, African American adults with asthma: what matters to them? Ann Allergy Asthma Immunol. 2014;112(1):35-39. doi:10.1016/j.anai.2013.10.016

30. Wamboldt FS, Bender BG, Rankin AE. Adolescent decision-making about use of inhaled asthma controller medication: results from focus groups with participants from a prior longitudinal study. J Asthma. 2011;48(7):741-750. doi:10.3109/02770903.2011.598204

31. George M, Keddem S, Barg FK, Green S, Glanz K. Urban adults' perceptions of factors influencing asthma control. J Asthma. 2015;52 (1):98-104. doi:10.3109/02770903.2014.947651

32. Axelsson M, Lötvall J, Lundgren J, Brink E. Motivational foci and asthma medication tactics directed towards a functional day. $B M C$ Public Health. 2011;11:809. doi:10.1186/1471-2458-11-809

33. Lingner H, Burger B, Kardos P, Criee CP, Worth H, HummersPradier E. What patients really think about asthma guidelines: barriers to guideline implementation from the patients' perspective. BMC Pulm Med. 2017;17(1):13. doi:10.1186/s12890-016-0346-6

34. Peláez S, Bacon SL, Aulls MW, Lacoste G, Lavoie KL. Similarities and differences between asthma health care professional and patient views regarding medication adherence. Can Respir J. 2014;21 (4):221-226. doi:10.1155/2014/738654

35. Peláez S, Bacon SL, Lacoste G, Lavoie KL. How can adherence to asthma medication be enhanced? Triangulation of key asthma stakeholders' perspectives. $J$ Asthma. 2016;53(10):1076-1084. doi:10.3109/02770903.2016.1165696

36. Peláez S, Lamontagne AJ, Collin J, et al. Patients' perspective of barriers and facilitators to taking long-term controller medication for asthma: a novel taxonomy. BMC Pulm Med. 2015;15:42. doi:10.1186/s12890-015-0044-9

37. Quaranta J, Wool M, Logvis K, Brown KK, Joshy D. Interpersonal influences on the asthma self-management skills of the rural adolescent. Online J Rural Nurs Health Care. 2014;14:97-122. doi:10.14574/ojrnhc.v14i2.281

38. Axelsson M. Personality and reasons for not using asthma medication in young adults. Heart Lung. 2013;42(4):241-246. doi:10.1016/j. hrtlng.2013.01.005

39. Blaakman SW, Cohen A, Fagnano M, Halterman JS. Asthma medication adherence among urban teens: a qualitative analysis of barriers, facilitators and experiences with school-based care. J Asthma. 2014;51(5):522-529. doi:10.3109/02770903.2014.885041

40. Choi TN, Westermann H, Sayles W, Mancuso CA, Charlson ME. Beliefs about asthma medications: patients perceive both benefits and drawbacks. J Asthma. 2008;45(5):409-414. doi:10.1080/02770900801971834

41. Koster ES, Philbert D, de Vries TW, van Dijk L, Bouvy ML. "I just forget to take it": asthma self-management need and preferences in adolescents. J Asthma. 2015;52(8):831-837. doi:10.3109/02770903.2015.1020388 
42. Murdoch J, Salter C, Cross J, Smith J, Poland F. Resisting medications: moral discourses and performances in illness narratives. Sociol Health Illn. 2013;35(3):449-464. doi:10.1111/j.1467-9566.2012.01499.x

43. Brown MT, Bussell JK. Medication adherence: WHO cares? Mayo Clin Proc. 2011;86(4):304-314. doi:10.4065/mcp.2010.0575

44. Kennedy J, Tuleu I, Mackay K. Unfilled prescriptions of medicare beneficiaries: prevalence, reasons, and types of medicines prescribed. J Manag Care Pharm. 2008;14(6):553-560. doi:10.18553/jmcp.2008.14.6.553

45. George M, Bender B. New insights to improve treatment adherence in asthma and COPD. Patient Prefer Adherence. 2019;13:1325-1334. doi:10.2147/PPA.S209532

46. Tilly-Gratton A, Nadon M, Houle A, Pelaez S, Ducharme F. What convinces parents of children with asthma to adhere to maintenance inhaled corticosteroids? Can J Resp Crit Care Sleep. 2018;2 (3):147-154. doi:10.1080/24745332.2018.1450101

47. Reach G. Is there an impatience genotype leading to non-adherence to long-term therapies? Diabetologia. 2010;53(8):1562-1567. doi:10.1007/s00125-010-1755-3

48. FitzGerald JM, Boulet LP, McIvor RA, Zimmerman S, Chapman KR. Asthma control in Canada remains suboptimal: the Reality of Asthma Control (TRAC) study. Can Respir J. 2006;13(5):253-259. doi:10.1155/ 2006/753083

49. Boulet LP. Perception of the role and potential side effects of inhaled corticosteroids among asthmatic patients. Chest. 1998;113 (3):587-592. doi:10.1378/chest.113.3.587

50. Wilson SR, Strub P, Buist AS, et al. Shared treatment decision making improves adherence and outcomes in poorly controlled asthma. Am $J$ Resp Crit Care Med. 2010;181(6):566-577. doi:10.1164/rccm. 200906-0907OC

51. Pinnock H. Supported self-management for asthma. Breathe. 2015;11 (2):98-109. doi:10.1183/20734735.015614

52. Gibson PG, Powell H. Written action plans for asthma: an evidence-based review of the key components. Thorax. 2004;59 (2):94-99. doi:10.1136/thorax.2003.011858

53. Goeman D, Jenkins C, Crane M, Paul E, Douglass J. Educational intervention for older people with asthma: a randomised controlled trial. Patient Educ Couns. 2013;93(3):586-595. doi:10.1016/j.pec.2013.08.014

54. Giraud V, Allaert FA, Roche N. Inhaler technique and asthma: feasability and acceptability of training by pharmacists. Respir Med. 2011;105(12):1815-1822. doi:10.1016/j.rmed.2011.07.004

55. Burkhart PV, Rayens MK, Oakley MG, Abshire DA, Zhang M. Testing an intervention to promote children's adherence to asthma self-management. $J$ Nurs Scholarsh. 2007;39(2):133-140. doi:10.1111/j.1547-5069.2007.00158.x

56. Morton RW, Elphick HE, Rigby AS, et al. STAAR: a randomised controlled trial of electronic adherence monitoring with reminder alarms and feedback to improve clinical outcomes for children with asthma Thorax. 2017;72(4):347-354. doi:10.1136/thoraxjnl-2015-208171

57. Chan AH, Stewart AW, Harrison J, Camargo CA, Black PN, Mitchell EA. The effect of an electronic monitoring device with audiovisual reminder function on adherence to inhaled corticosteroids and school attendance in children with asthma: a randomised controlled trial. Lancet Respir Med. 2015;3(3):210-219. doi:10.1016/ S2213-2600(15)00008-9

\section{Patient Preference and Adherence}

\section{Publish your work in this journal}

Patient Preference and Adherence is an international, peer-reviewed, open access journal that focuses on the growing importance of patient preference and adherence throughout the therapeutic continuum. Patient satisfaction, acceptability, quality of life, compliance, persistence and their role in developing new therapeutic modalities and compounds to optimize clinical outcomes for existing disease
58. Foster JM, Usherwood T, Smith L, et al. Inhaler reminders improve adherence with controller treatment in primary care patients with asthma. J Allergy Clin Immunol. 2014;134(6):1260-1268.e1263. doi:10.1016/j.jaci.2014.05.041

59. Fink JB, Rubin BK. Problems with inhaler use: a call for improved clinician and patient education. Respir Care. 2005;50(10): 1360-1375.

60. Plaza V, Sanchis J, Roura P, et al. Physicians' knowledge of inhaler devices and inhalation techniques remains poor in Spain. $J$ Aerosol Med Pulm Drug Deliv. 2012;25(1):16-22. doi:10.1089/jamp. 2011.0895

61. Hanania NA, Wittman R, Kesten S, Chapman KR. Medical personnel's knowledge of and ability to use inhaling devices: metered-dose inhalers, spacing chambers, and breath-actuated dry powder inhalers. Chest. 1994;105(1):111-116. doi:10.1378/chest.105.1.111

62. Sovani MP, Whale CI, Oborne J, et al. Poor adherence with inhaled corticosteroids for asthma: can using a single inhaler containing budesonide and formoterol help? Br J Gen Pract. 2008;58 (546):37-43. doi:10.3399/bjgp08X263802

63. van der Palen J, Klein JJ, van Herwaarden CL, Zielhuis GA, Seydel ER. Multiple inhalers confuse asthma patients. Eur Respir J. 1999;14(5):1034-1037. doi:10.1183/09031936.99.14510349

64. Marceau C, Lemière C, Berbiche D, Perreault S, Blais L. Persistence, adherence, and effectiveness of combination therapy among adult patients with asthma. $J$ Allergy Clin Immunol. 2006;118 (3):574-581. doi:10.1016/j.jaci.2006.06.034

65. Stempel DA, Stoloff SW, Carranza Rosenzweig JR, Stanford RH, Ryskina KL, Legorreta AP. Adherence to asthma controller medication regimens. Respir Med. 2005;99(10):1263-1267. doi:10.1016/j. rmed.2005.03.002

66. O'Byrne PM, Jenkins C, Bateman ED. The paradoxes of asthma management: time for a new approach? Eur Respir J. 2017;50 (3):1701103. doi:10.1183/13993003.01103-2017

67. Beasley R, Bird G, Harper J, Weatherall M. The further paradoxes of asthma management: time for a new approach across the spectrum of asthma severity. Eur Respir J. 2018;52:1800694. doi:10.1183/ 13993003.00694-2018

68. Aldridge RE, Hancox RJ, Robin Taylor D, et al. Effects of terbutaline and budesonide on sputum cells and bronchial hyperresponsiveness in asthma. Am J Respir Crit Care. 2000;161(5):1459-1464. doi:10.1164/ajrccm.161.5.9906052

69. Stanford RH, Shah MB, D'Souza AO, Dhamane AD, Schatz M. Short-acting $\beta$-agonist use and its ability to predict future asthmarelated outcomes. Ann Allergy Asthma Immunol. 2012;109 (6):403-407. doi:10.1016/j.anai.2012.08.014

states are major areas of interest for the journal. This journal has been accepted for indexing on PubMed Central. The manuscript management system is completely online and includes a very quick and fair peer-review system, which is all easy to use. Visit http:// www.dovepress.com/testimonials.php to read real quotes from published authors. 